\title{
Publisher Correction: Biomolecular modeling thrives in the age of technology
}

Tamar Schlick (1) and Stephanie Portillo-Ledesma

Correction to: Nature Computational Science https://doi.org/10.1038/s43588-021-00060-9, published online 20 May 2021.

In the version of this Perspective initially published, there were omissions in the credits provided for Fig. 1. The caption indicated that the figure was adapted with permission from ref. 1, Cambridge University Press, but did not present separate credit for some images presented within the overall timeline. The Fig. 1 caption has been amended as follows: "Figure adapted with permission from ref. 1, Cambridge Univ. Press (timeline); Angela Barragan Diaz, The University of Chicago, NIC Center for Macromolecular Modeling and Bioinformatics ( $b c 1$ (in membrane)); ref. 147, American Chemical Society (12-bp DNA); ref. 154, under a Creative Commons license CC BY 4.0 (CypA/CA complex); ref. 7, under a Creative Commons license CC BY 4.0 (HIV-1 capsid); ref. 153, Springer Nature Ltd (NMDA); courtesy of Lorenzo Casalino, UC San Diego (influenza A, top); ref. 144, Elsevier (25-bp DNA); ref. 149, Wiley (Fip35); ref. 152, Cell Press (influenza A, bottom); ref. 151, PLOS (Nuclear pore complex); ref. 39, Wiley (GATA4 gene)."

The error has been corrected in the online version of the article.

Published online: 16 November 2021

https://doi.org/10.1038/s43588-021-00170-4

(c) Springer Nature America, Inc. 2021 